\title{
Prolonged exclusive breast feeding and heredity as determinants in infantile atopy
}

\author{
E SAVILAHTI, V-M TAINIO, L SALMENPERÄ, M A SIIMES, AND J PERHEENTUPA \\ Children's Hospital, University of Helsinki, Finland
}

SUMmaRY We followed 183 infants for two years, 31 of whom were breast fed less than three and a half months (median 70 days; short breast feeding group) and a further 31 of whom were exclusively breast fed for more than nine months (long breast feeding group). We assessed heredity for atopy, number of infections, and duration of breast feeding as determinants of atopy. During the first year of life 14 infants has signs of atopy. During the second year parents reported signs of atopy in a further 31 . Heredity was the only significant predictor of atopy. Atopy was seen in $33 \%$ of infants with a positive heredity and in $16 \%$ without family history for atopy. The duration of breast feeding affected the incidence of atopy only among the infants without family history for atopy: fewer in the short breast feeding group $(1 / 18)$ had atopy than in the long breast feeding group (5/13). Duration of breast feeding did not associate with incidence of respiratory infections. Diarrhoea was more common in the short breast feeding group than in the long breast feeding group during the first year of life. We conclude that prolonging exclusive breast feeding from the median of 70 days to nine months did not contribute to the prevention of infantile atopy and respiratory tract infections.

Human milk is the best nutrition for the full term human infant during the first months of life, but nutritional needs can also be met accurately by a well balanced formula. The non-human proteins in the formulas, however, always provoke immune reactions in the infants and, furthermore, the formulas lack the protective agents of human milk. ${ }^{1}$ Many studies have indicated that infants on cow's milk or formulas based on cow's milk have more gastrointestinal and also probably more respiratory infections than breast fed infants. ${ }^{2-6} \mathrm{~A}$ higher number of infections as well as immune reactions to cow's milk proteins may pave the way for atopy, which may be more common in infants who are weaned early than in breast fed infants. ${ }^{4} 78-13$ This has been disputed, however, ${ }^{714}$ particularly in more recent studies. ${ }^{15-20}$

During a prospective nutritional study on 198 infants ${ }^{21}$ we carefully recorded all signs of atopy and infections and studied the interrelations with the feeding regimens.

\section{Patients and methods}

Follow up. Participants were recruited from mothers who had given birth to healthy babies at the department of obstetrics of the University of Helsinki. They were invited to participate on certain, predetermined days. Prerequisites for inclusion were that they were non-smokers, lived in the city of Helsinki, did not have any major disease (atopy was not a reason for exclusion), and had a full term, appropriate for gestational age baby. Altogether $90 \%$ of those asked agreed to participate. The goal was to obtain 200 newborn infants for the study. Two families dropped out during the first year, leaving 198 infants.

The infants visited the paediatric clinic at 2, 4, 6, 9 , and 12 months of age. At each visit all relevant data were recorded and a physical examination made. We provided all medical care-for example, treatment for respiratory infections-during the first year. At a mean age of 2.3 years 60 of the infants were again studied. The parents of all 198 infants were asked to complete a questionnaire about the health of their infant during the second year of life; 15 families failed to return the questionnaire.

Feeding. We encouraged mothers to carry on exclusive breast feeding as long as possible to study its nutritional value. Exclusively breast fed infants received no formula milk or other complementary 
food. Their number gradually fell to 101 by the age of 6 months and to 31 by the age of 9 months (long breast feeding group). The median duration of exclusive breast feeding in this group was 323 days, and most were fully weaned only after 12 months.

The infants who were completely weaned followed a standard dietary programme, which included an adapted formula with $16 \mathrm{~g} / 1$ protein (Valio Co Ltd, Helsinki, Finland), fruit and vegetables from 3 months, and cereals and meat from 5 months; pasteurised whole cow's milk was substituted for the formula from 9 months. Thirty one infants were completely weaned by 3.5 months; they were all breast fed from birth, exclusively for a median of 11 days and at least partially for 70 days (range three to 105 days; short breast feeding group). The cut off point of 3.5 months was chosen to obtain an appropriate number of infants for comparison.

Heredity for atopy. Seventy nine infants had one or both parents or a sibling with atopic symptoms (bronchial asthma, allergic rhinitis, atopic dermatitis, or recurrent gastrointestinal symptoms occurring within one hour of ingesting particular foods).

Environment. Social class, education of parents, and housing conditions of the infants were recorded. The type of day care they received during three month periods was classified as home care, day care in a small group, and day care in a large group outside the home. There was practically no smoking in the homes, and smoking was forbidden in the day nurseries.

The social class of the families (determined on the basis of the father's position) was similar in both the short and long breast feeding groups ( $42 \%$ and $44 \%$, respectively, in the highest social class). The mean age of the mothers in the long breast feeding group was significantly higher compared with those in the short breast feeding group $(30.9 v 27.7$ years, $p=0 \cdot 001)$. Also the number of mothers with academic or other tertiary education was higher in this group $(58 \% \vee 42 \%, \mathrm{p}<0 \cdot 05)$.

Atopy. Atopy was diagnosed if the infant had the following:

(1) Pruritic dry dermatitis, consisting of erythema or papules outside the nappy area, which was present on two or more visits during the first year.

(2) A history of urticarial eruption.

(3) Three or more episodes of wheezy bronchitis during one year.

(4) Three or more of the following symptoms: rhinorrhoea for more than one month; itching or watering eyes; gastrointestinal symptoms provoked by foods; one or two wheezy attacks of bronchitis during one year.

(5) Dermatitis described by the parents to be compatible with atopic eczema during the second year.

Statistical analysis. We used $\chi^{2}$ and $t$ tests for comparisons.

The predicting factors for atopy were analysed by stepwise logistic regression. The following variables were tested as basic variates:

(1) Education of mothers.

(2) Size of home.

(3) Type of day care (period of more than six months during the second year).

(4) Heredity for atopy.

(5) Age at first exposure to cow's milk (formula).

(6) Age at start of regular formula feeding.

(7) Total duration of breast feeding.

(8) Age at introduction of solid foods.

(9) Number of respiratory tract infections during the first year.

The predictive variates were treated in the first analysis as continuous (variables 2, 5-8, and 9) or categorical (variables 1, 3, and 4). In further analysis all variates were treated as categorical.

\section{Results}

Atopic manifestation. Fourteen infants had signs of atopy during the first year ( $7 \%$ of total) and a further $31(17 \%)$ had signs suggestive of atopy during the second year. Only three infants had symptoms suggestive of asthma.

Logistic regression analysis showed heredity for atopy to be the only significant factor for predicting the occurrence of atopy $\left(\chi^{2}=4.33, \mathrm{df}=1, \mathrm{p}<0.05\right)$, and the relative risk for atopy among those with a positive heredity was $1.41 \quad(95 \%$ confidence limits $=1 \cdot 00-1 \cdot 98)$. More infants with heredity for atopy had signs of atopy during the second year than those without heredity $(p=0 \cdot 04)$ (Table 1$)$. Exclusive breast feeding lasting more than six months was a probable risk factor for atopy, with a relative risk of $1.37(95 \%$ confidence limits $=0 \cdot 96-1 \cdot 96)$ $\left(\chi^{2}=3 \cdot 44, \mathrm{df}=1, \mathrm{p}<0 \cdot 1\right)$. The effect of feeding on the incidence of atopy was seen among infants who did not have a family history of atopy, the incidence of infantile atopy being higher in the long breast feeding group (exclusively breast fed for more than nine months) than in the short breast feeding group $(p=0.06)($ Table 2$)$. After the effect of heredity had been disregarded, atopic manifestations during the first year were more common among infants in the long breast feeding group $(p=0.02)$ (Table 1$)$. The proportion of infants with heredity for atopy in the two groups was similar (Table 2). 
Table 1 Atopy in groups with varying duration of exclusive or total breast feeding, in infants with heredity for atopy, and in groups with different incidence of respiratory infections

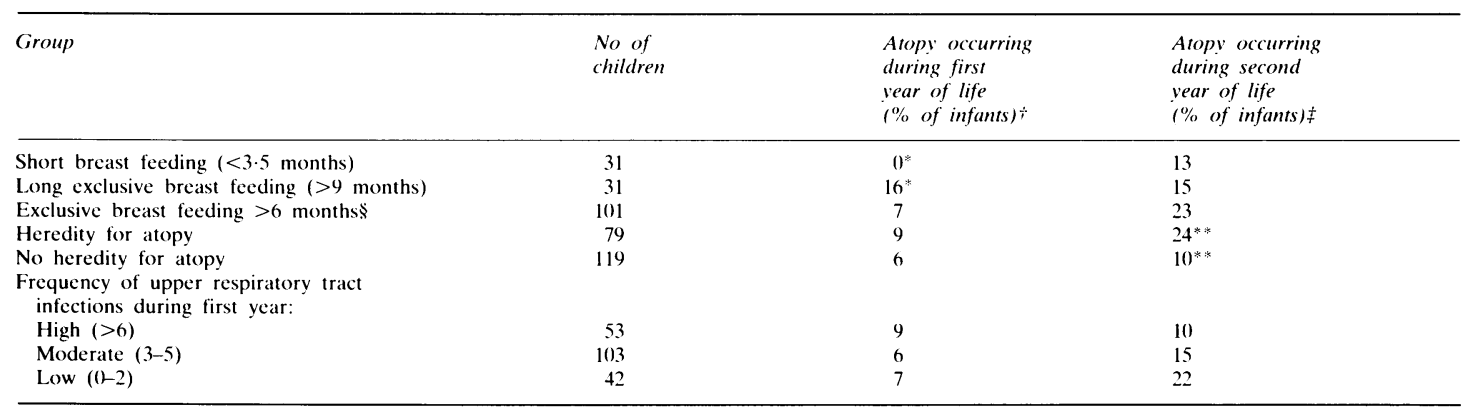

$\left.{ }^{*} \mathrm{p}=0\right) \cdot() 2 ; * * \mathrm{p}=0 \cdot(14$.

information available for 198 infants.

Information available for 183 infants.

$\$$ Median duration of exclusive breast feeding was 278 days: most infants were fully weaned after 12 months.

Table 2 Incidence of atopy during the first two years according to duration of exclusive and total breast feeding and heredity for atopy in selected groups of infants

\begin{tabular}{|c|c|c|c|c|c|c|}
\hline \multirow[t]{2}{*}{ Type of breast feeding } & \multicolumn{3}{|c|}{ No heredity for atopy } & \multicolumn{3}{|c|}{ Heredity for atopy } \\
\hline & $\begin{array}{l}\text { No atopy } \\
(\text { No) }\end{array}$ & $\begin{array}{l}\text { Atopy } \\
\text { (No) }\end{array}$ & Incidence $(\%)$ & $\begin{array}{l}\text { No atopy } \\
(\text { No) }\end{array}$ & $\begin{array}{l}\text { Atopy } \\
\text { (No) }\end{array}$ & Incidence $(\%)$ \\
\hline \multicolumn{7}{|l|}{ Short total } \\
\hline ( $<3.5$ months $)$ & 18 & 1 & $5 *$ & 9 & 3 & 25 \\
\hline$<6$ Months & 26 & 4 & 13 & 12 & 3 & 20 \\
\hline$>6$ Months exclusive & 47 & 12 & 20) & 30 & 13 & 30 \\
\hline \multicolumn{7}{|l|}{ Long exclusive } \\
\hline (>9 months) & 13 & 5 & 28 & 9 & 4 & 31 \\
\hline
\end{tabular}

The occurrence of atopy did not differ significantly in infants with a low, moderate, or high incidence of upper respiratory tract infections (Table 1). Logistic analysis showed that this factor had no significant risk for atopy. The other seven variables tested (see methods), including age at introduction of solid foods, were not risk factors either for atopy.

Infections. Fewer of the infants with long exclusive breast feeding had acute diarrhoea during the first year compared with those with short breast feeding $(5 / 31 v 12 / 31, p=0.06)$. The number of other infections in these feeding groups was similar. In the whole study group of 198 infants the mean number of upper respiratory tract infections during the first year was 4.3 and during the second year was $3 \cdot 0$. The respective figures for otitis media were 0.4 and 1.5 and for diarrhoea were 0.4 and 0.6 . The infants received on average 0.5 treatments with antibiotics during the first year and $2 \cdot 2$ during the second. The number of infections was similar in infants with and without atopy. The group with atopy, however, may have been treated more often with antibiotics during infancy. The mean number of treatments during the first two years was $4 \cdot 2$ for those with and $2 \cdot 2$ for those without atopy $(p=0 \cdot 05)$.

\section{Discussion}

Since the early 1970 s breast feeding has regained its popularity. In Finland the proportion of infants breast fed for six months has grown from less than $10 \%$ in 1970 to $25 \%$ in 1977 and to $69 \%$ thereafter. Prolongation of maternity leave and change in attitudes towards artificial feeding have been largely responsible for this. Today, the message of the presumed health benefits of breast feeding is spread through popular magazines and baby health clinics, putting great pressure on nursing mothers to carry on breast feeding for as long as possible. It is therefore not surprising that when we encouraged the mothers in our study to breast feed their infants exclusively half of them did so for six months and 31 for nine months.

Our study group was selected to include only 
healthy newborn infants of non-smoking mothers who had no major illness. Participation was high $(90 \%)$ and the number of dropouts low $(1 \%)$. No bias was likely to be caused by these factors. We believe, therefore, that our results give a realistic picture of the incidence of atopy and infectious diseases among healthy infants living in a developed urban society.

Several earlier studies have shown that breast feeding (exclusive or mixed) prevents or postpones the development of atopy. ${ }^{4-13}$ According to most studies, however, the source of the artificial feeding (cow's milk or soy) does not influence the incidence of atopy. ${ }^{13} 1422$ Earlier studies have also shown that breast feeding does not prevent atopy. ${ }^{15-20}$ One recent study ${ }^{20}$ and our present results even show the contrary-namely, fewer atopic signs in early weaned infants.

Some studies have shown that the early introduction of solid foods is a risk factor for atopy, ${ }^{15}{ }^{23} \mathrm{but}$ we did not find any such association. We did, however, introduce solid foods late and gradually, which may have an influence.

We speculate that the lower protein concentration of presently used formulas compared with earlier ones makes them less antigenic. This may partly explain why the artificial feeding did not provoke atopy as often as in earlier studies.

In our study, as in many others, heredity for atopy was significantly associated with the occurrence of infantile atopy. ${ }^{11-1820} 22$ Earlier studies have suggested that breast feeding is particularly protective against atopy in infants with a positive heredity for atopy, ${ }^{11-13} 2022$ but we saw no evidence of this effect. On the contrary, in infants without such heredity a short duration of breast feeding was associated with a lower incidence of atopy, whereas a long duration of breast feeding was not. We also considered the possibility that the mothers tried to treat their infants' atopic like symptoms by prolonging breast feeding. The motivation to breast feed, however, was high in all mothers and breast feeding was stopped when the amount of milk became insufficient for the baby. Sensitisation through breast milk could be another explanation. Breast milk carries small quantities of food proteins in antigenic form, ${ }^{1}$ which may provoke synthesis of $\mathrm{IgE}$ antibodies and clinical hypersensitivity. In fact, in a recent study this type of sensitisation was seen in $10 \%$ of breast fed infants. ${ }^{24}$

The protection by human milk against infectious gastrointestinal diseases is well known, particularly in developing countries and in infants with malnutrition. ${ }^{2-4} 7$ We also found that fewer infants on prolonged breast feeding had acute diarrhoea during the first year than infants put on formula before 3.5 months of age.

Some studies suggest that human milk may protect against respiratory tract infections, ${ }^{24}$ in particular otitis media, ${ }^{6}$ but these findings have been disputed. ${ }^{7}$ It is generally agreed that colostrum milk antibodies are not absorbed from human milk, ${ }^{1}$ and hence the protective effect of breast milk is difficult to explain. We did not see any difference in the rate of respiratory infections between infants with short and long breast feeding.

In conclusion, our study showed that in a highly hygienic society prolonged exclusive breast feeding had no advantage over short breast feeding with regard to the risk of atopy or respiratory infections during the first two years of life. We emphasise that our results may not apply to undeveloped societies where the incidence of intestinal infections is much higher and malnutrition of mothers and infants common.

The study was supported by grants from the Sigrid Juselius Foundation, the Foundation for Paediatric Research, and the Foundation for Nutritional Research, Helsinki, Finland. The formula was kindly donated by Valio Co Ltd and canned solid foods (given to supplement breast feeding to some of the infants) by Orion Co, Chymos, Helsinki, Finland.

\section{References}

1 Hanson LA, Ahlstedt S, Andersson B, et al. Protective factors in milk and the development of immune system. Pediatrics 1985;76:(Suppl):172-6.

2 Grulec CG, Sanford HN, Herron PH. Breast and artificial feeding. Influence on morbidity and mortality of twenty thousand infants. JAMA 1934;103:735-9.

${ }^{3}$ Cunningham AS. Morbidity in breast-fed and artificially fed infants. J Pediatr 1977:90:726-9.

4 Chandra RK. Prospective studies for the effect of breast-feeding on incidence of infection and allergy. Acta Paediatr Scand 1977;68:691-4.

${ }^{5}$ Frank AL. Taber LH. Glenzen WP, Kasel GL. Wells CR. Paredes A. Breast-feeding and respiratory virus infection. Pediatrics 1982:70:239-45.

" Saarinen UM. Prolonged breast feeding as prophylaxis for recurrent otitis media. Acta Paediatr Scand 1982:71:567-71.

${ }^{7}$ Kovar MG, Serdula MK. Marks JS. Fraser DW. Review of the epidemiologic evidence for an association between infant feeding and infant health. Pediatrics 1984:74(Suppl):615-38.

* Grulec CG. Sanford HN. The influence of breast and artificial feeding on infantile eczema. $J$ Pediatr 1936;9:223-5.

"Johnstone DE, Dutton AM. Dictary prophylaxis of allergic discase in children. $N$ Engl $J$ Med 1966:274:715-9.

11) Matthew DJ. Taylor B. Norman AP, Turner MW, Soothill JF. Prevention of eczema. Lancet 1977;i:312-24.

"Saarinen UM, Kajosaari M, Backman A, Siimes MA. Prolonged breast-feeding as prophylaxis for atopic diseasc. Lancet 1979:ii:163-6.

12 Kaufman HS. Frick OL. Prevention of asthma. Clin Allergy 1981:11:549-53.

13 Grusky FL. Comparison of breast, cow, and soy feedings in the prevention of onset of allergic disease. Clin Pediatr 1982;21: 486-91. 
it Halpern SR, Sellars WA, Johnson RB, Anderson DW, Saperstein S. Reisch JS. Development of childhood allergy in infants fed breast. soy or cow milk. J Allergy Clin Immunol 1973:51:139-51.

15 Ferguson DM. Horwood LJ, Beautriais AL, Shannon FT. Taylor B. Eczema and infant diet. Clin Allergy 1981:11:325-31.

16 Hide DW. Guyer BM. Clinical manifestations of allergy related to breast and cow's milk feeding. Arch Dis Child 1981:56:172-5.

17 Kramer MS. Moroz B. Do breast-feeding and delayed introduction of solid foods protect against subsequent atopic eczema? $J$ Pediatr 1981:98:546-50).

is Gordon RR, Noble DA. Ward AM. Allen R. Immunoglobulin $E$ and the eczema-asthma syndrome in early childhood. Lancet 1982:i:72-4.

19 Ferguson DM, Horwood LJ, Shannon FT. Asthma and infant dict. Arch Dis Child 1983:58:48-51.

21) Taylor B, Wadsworth J. Golding J. Butler N. Breast feeding. eczema, asthma, and hayfever. $J$ Epidemiol Community Health 1983:37:95-9.

2 Salmenperä L. Perheentupa J, Siimes MA. Exclusively breastfed healthy infants grow slower than reference infants. Pediatr Res 1985;19:307-12.

${ }^{22}$ Kjellman N-IM, Johansson SGO. Soy versus cow's milk in infants with biparental history of atopic disease: development of atopic disease and immunoglobulins from birth to 4 years of age. Clin Allergy 1979;9:347-58.

23 Saarinen UM, Kajosaari M. Does dietary elimination in infancy prevent or only postpone a food allergy? A study of fish and citrus allergy in 375 children. Lancet 1980):i:166-7.

${ }^{24}$ Hattevig G, Kjellman B. Johansson SGO. Björksten B. Clinical symptoms and IgE responses to common food proteins in atopic and healthy children. Clin Allergy 1984:14:551-9.

Correspondence to Dr E Savilahti, Children`s Hospital, SF-(0)290 Helsinki, Finland.

Received 17 October 1986

\section{Commentary}

\section{T J DAVID}

\section{Booth Hall Children's Hospital, Manchester}

The notion that atopic disease can be prevented by breast feeding is surrounded by confusion. There is a pitiful lack of good objective data. Not one study of this subject is without serious defect, and those from the greatest enthusiasts for this new religion are often the most riddled with flaws. Objections to previous studies, where the incidence of eczema or atopic disease was compared in babies fed in different ways, include:
(1) Observer bias. Doctors known to be protagonists of breast feeding decided whether to classify an infant's skin rash as 'eczema' or not, a procedure notorious for its lack of objectivity, in the full knowledge of both the family history and whether the baby was breast or bottle fed.

(2) Misleading information based on inclusion of minor forms of disease. Studies compared the total incidence of diseases such as eczema or asthma in babies fed in different ways, but mothers fear severe cases. It would be a waste of time to find a technique that abolished hairy patches over the sacrum but failed to prevent spina bifida.

(3) Self selection bias. Inevitably, mothers with a strong family history are the ones most motivated to try a possible preventive measure and yet their offspring are at the greatest risk of being affected, making comparison with another group difficult or impossible.

In this context, there is only one fact that is really clear about breast feeding, which has been known for 50 years or more but has been recently rediscovered. This is that in certain women ingested food antigens can pass into the milk. Maternal avoidance of the food in question is followed by remission of atopic disease in the infant, and re-exposure is followed by relapse. It is probable, though unproven, that mothers susceptible to this problem are themselves atopic. Thus the very women who might most wish to prevent atopic disease in their offspring may be just the ones in whom breast feeding contributes to the production of atopic disease.

The latest paper from Helsinki is by no means free from defects, including some of the ones described above, but it is better than most. The authors' carefully worded conclusion is that prolonged breast feeding did not prevent atopy. For cases where there was no family history of atopy, however, the greater incidence of atopic disease in those infants receiving prolonged exclusive breast feeding almost reached significance. The message for obstetricians and paediatricians is clear. The idea that eczema or asthma can be prevented by breast feeding, whether or not accompanied by other forms of antigen avoidance such as the delayed introduction of solids, seriously lacks objective validation. 